\title{
Waterbath Design equipped With Temperature Distribution Monitor
}

\section{(Temperature and Timer Control Parameters)}

\author{
Febri Indiani", Dyah Titisari, Lamidi \\ Department of Electromedical Engineering Poltekkes Kemenkes, Surabaya \\ Jl. Pucang Jajar Timur No. 10, Surabaya, 60245, Indonesia \\ \#febriindiani07@,gmail.com, ti2_sari@yahoo.com, justlamidi@yahoo.co.id
}

\begin{abstract}
Waterbath is a device used to create a constant temperature. This tool is used to incubates in microbiology analysis. Temperature is maintained according to the desired range. The heating element is controlled by the heater driver. This module is created by using Arduino Atmega 328 as a minimum system and time controller, Using a PID controller as temperature control, and using a DS18B20 sensor as a temperature sensor. The design of this study uses pre-experimental methods after only design research. The measurement results are done by comparing the module with a standard measurement instrument that produces the biggest \% error in setting temperature of $37^{\circ} \mathrm{C}$ which is equal to $1.21 \%$, it is related to the boundary between water temperature and temperature setting too short which is affected by the DS18B20 temperature sensor reader that need time, to get a stable temperature reading. The minimum $\%$ error located at $60{ }^{\circ} \mathrm{C}$, because to reach the temperature setting needs a long time so that DS18B20 the sensor reading is stable of setting temperature which is equal to $0.11 \%$. The value \% error of the timer is $3.4 \%$ which the amount of the error is affected by the number of DS18B20 which is used and the delay from the microcontroller. Based on the results obtained this module can be used properly because still on the maximum limit error value less than $5 \%$.
\end{abstract}

Keywords-Waterbath; Timer; Temperature Control; DS18B20 Sensor

\section{INTRODUCTION}

Waterbath is a device whose main function is to create a constant temperature and is used for incubation in the microbiological analysis [1]. Waterbath works by heating water with a heater until the water temperature rises and matches the temperature set. The heater will stop heating water when the specified time has been reached [2]

In the previous study, the water bath tool that had been made still had a temperature range that was not too high, only at $30^{\circ} \mathrm{C}$ $-40^{\circ} \mathrm{C}$ so that incubation requiring temperatures above $40^{\circ} \mathrm{C}$ could not be done. It is still limited to one sample so that the water bath is made only for that sample. Still using an on-off control system so that the possibility of overload often occurs. Using an LM35 sensor whose output is still in the analog form so that in this case it still needs a circuit that is a conditioning circuit for analog signals.

In 2011 the water bath module was made by Agus Salim's Tsalits with the title "Waterbath Aircraft Modification" [3]. Waterbath is only designed for time and temperature control systems. For temperature control systems still, use the on-off system and the temperature settings used only at temperatures of $30^{\circ} \mathrm{C}$ and $40^{\circ} \mathrm{C}$.

In 2011, the water bath module was made by Catur Andreas. The Waterbath can fill and empty the water in the chamber automatically according to the water level indicator, the temperature of the device is $30^{\circ} \mathrm{C}-40^{\circ} \mathrm{C}$. The disadvantage of the module is that the temperature selection only ranges from $30^{\circ} \mathrm{C}-40^{\circ} \mathrm{C}$, so the analyst cannot choose a temperature higher than that temperature [4].

In 2014 , the water bath module was created by Carina Febriana with the title "Modification of Digital-Based Waterbath with Timing", [5] This module is designed to be limited to just one sample so that other samples cannot be done using this module.

In 2015, the water bath module was made by Ani Maulidia entitled "Waterbath Equipped with Safety Control and Arduino Based Water Level Indicators" [6]. This module uses the LM35 sensor and still uses the on-off control as temperature control so that the possibility of overload often occurs.

Based on the identification of the problems above, the writer wants to make a tool "Waterbath Design Equipped with Temperature Distribution Monitor (Temperature Control Parameters and Timers)". This module is made using a DS18B20 sensor as a sensor to detect the water temperature on the water bath. used the PID control as a temperature controller on the water bath.

The creation of this module is expected to maximize the performance of the Waterbath, and ensure that the temperature is stable at the specified set point. 


\section{MATERIALS AND METHODS}

\section{A. Experimental Setup}

This study used a digital thermometer as measuring for temperature and a stopwatch as measuring for a timer. Measuring was done 6 times a minute after temperature reached the set point.

\section{1) Materials and Tool}

This study is used an Arduino Atmega 328 as a system controller and control timer. Used a DS18B20 sensor as a temperature sensor. And used tubular type heater with specification voltage $220 \mathrm{~V}, 1000$ watt.

\section{2) Experiment}

In this study, after the design was completed then the temperature response of this device was tested using a digital thermometer with all setting $\left(37^{\circ} \mathrm{C}, 40{ }^{\circ} \mathrm{C}, 45{ }^{\circ} \mathrm{C}, 50{ }^{\circ} \mathrm{C}, 55^{\circ} \mathrm{C}\right.$, $60{ }^{\circ} \mathrm{C}$ ). And the timer response was tasted using a stopwatch with all setting (10 minute and 15 minutes).

\section{B. The Diagram Block}

In this research, the water bath temperature and timer setting used up, down and enter buttons as shown in Fig. 1. After that, the microcontroller will be read the water temperature sensor of the water heater and the results will be displayed on the LCD. When a set temperature is reached, the heater will stop working, otherwise, if a fixed temperature has not been reached, the heater will work. The heater also stops working when the timer setting has been completed and the buzzer sounds, to mark the process completed.

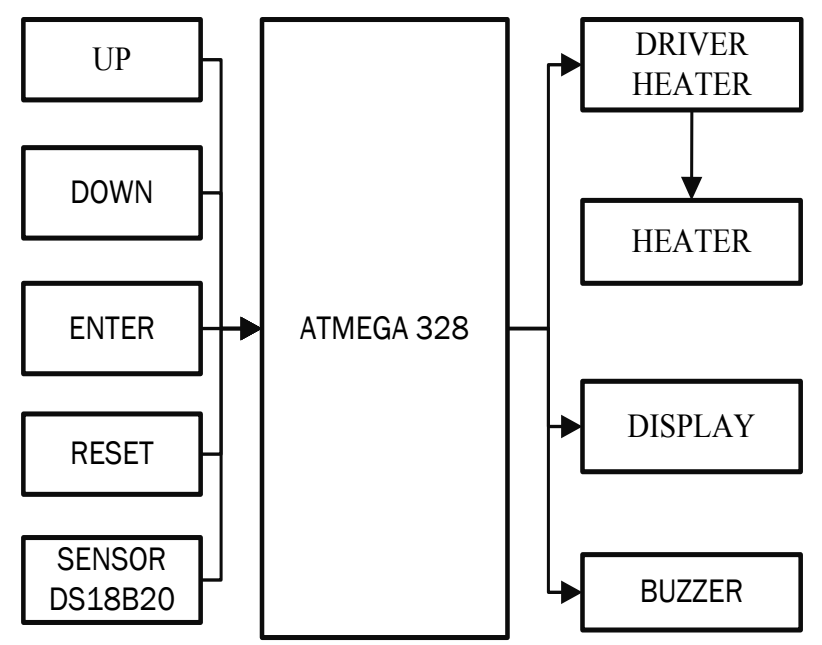

Fig. 1. The diagram block of the water bath

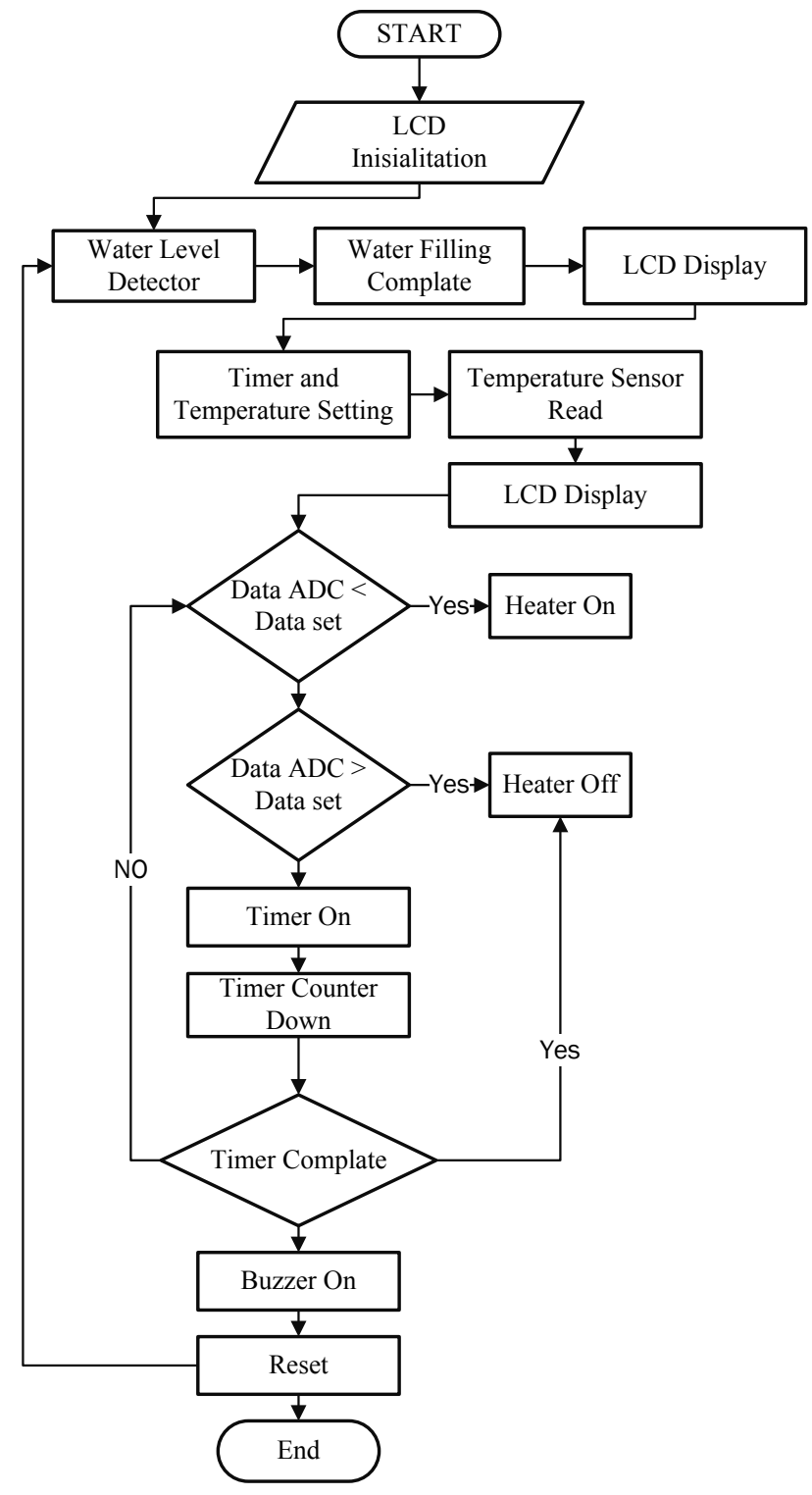

Fig. 2. The Flowchart of the Arduino Program

\section{The Flowchart}

The Arduino program was built based on the flowchart as shown in Fig. 2. After the initialization of the Arduino, the program will detect water level. If the water level is met, the temperature set and timer can be done. The temperature sensor will be doing readings and displayed on the LCD. If the ADC data is readable by microcontroller less than setting temperature, the heater will actively warm up. Whereas if the ADC data is readable on microcontroller more than setting temperature, the heater will be off. The timer will work when the setting temperature has been reached and start counting down, if the timer is spent, the incubation process is finished. The heater turns off and the buzzer sounds. If the timer has not run out, the microcontroller will still adjust the $\mathrm{ADC}$ data with the setting data, so that the heater stays on. 


\section{Circuit}

The important part of this development is the analog circuit which describes in Fig. 3 (Driver heater)

\section{1) Driver Heater}

The driver heater circuit is shown in figure 3. Works for heater controller. this circuit uses a BD140 which takes a logic of $>0.7$ volts for saturation. This driver used SSR to interface between circuits that use low power with circuits that use high power.

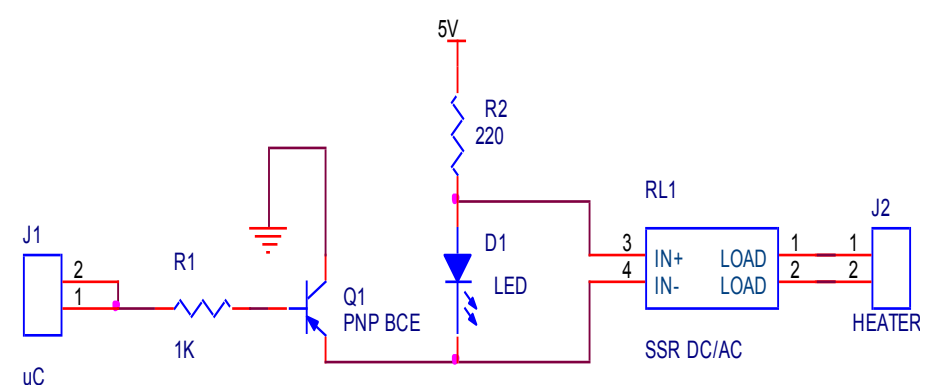

Fig. 3. Driver Heater

\section{RESULTS}

In this study, the water bath has been tested using Digital temperature for temperature parameter and stopwatch for timer parameter. The result shows that the water bath is feasible to incubation microbiology sample

\section{1) The Listing Program for Driver Heater}

The listing program for Driver Heater was shown in the Listing Program 1. The program used a PID controller to Temperature control. As for the method used trial and error to find $\mathrm{KP}, \mathrm{KI}$, and $\mathrm{KD}$ value.

Listing program 1. Program For Driver Heater

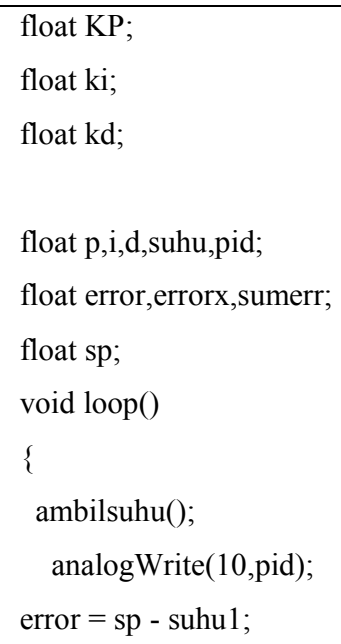

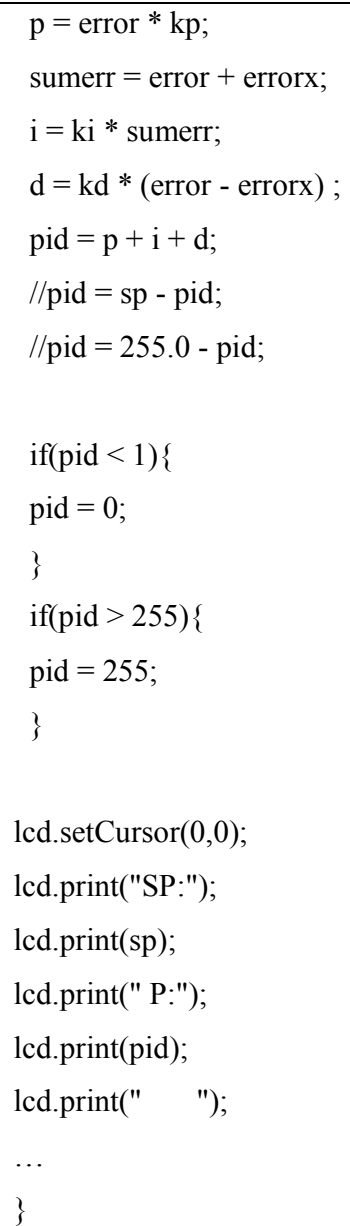

\section{2) The listing program for timer}

The Listing program for timer was shown as Listing Program 2. The modules used Arduino program to control the timer.

Listing Program 2. Program for timer

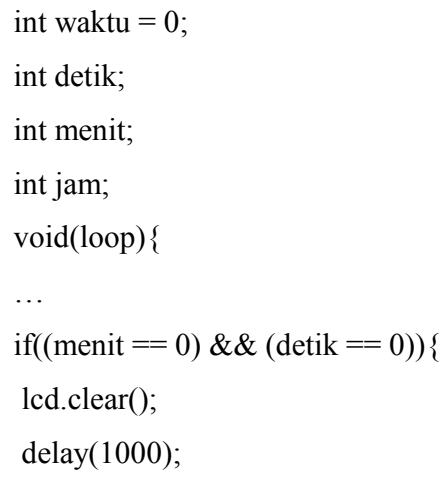




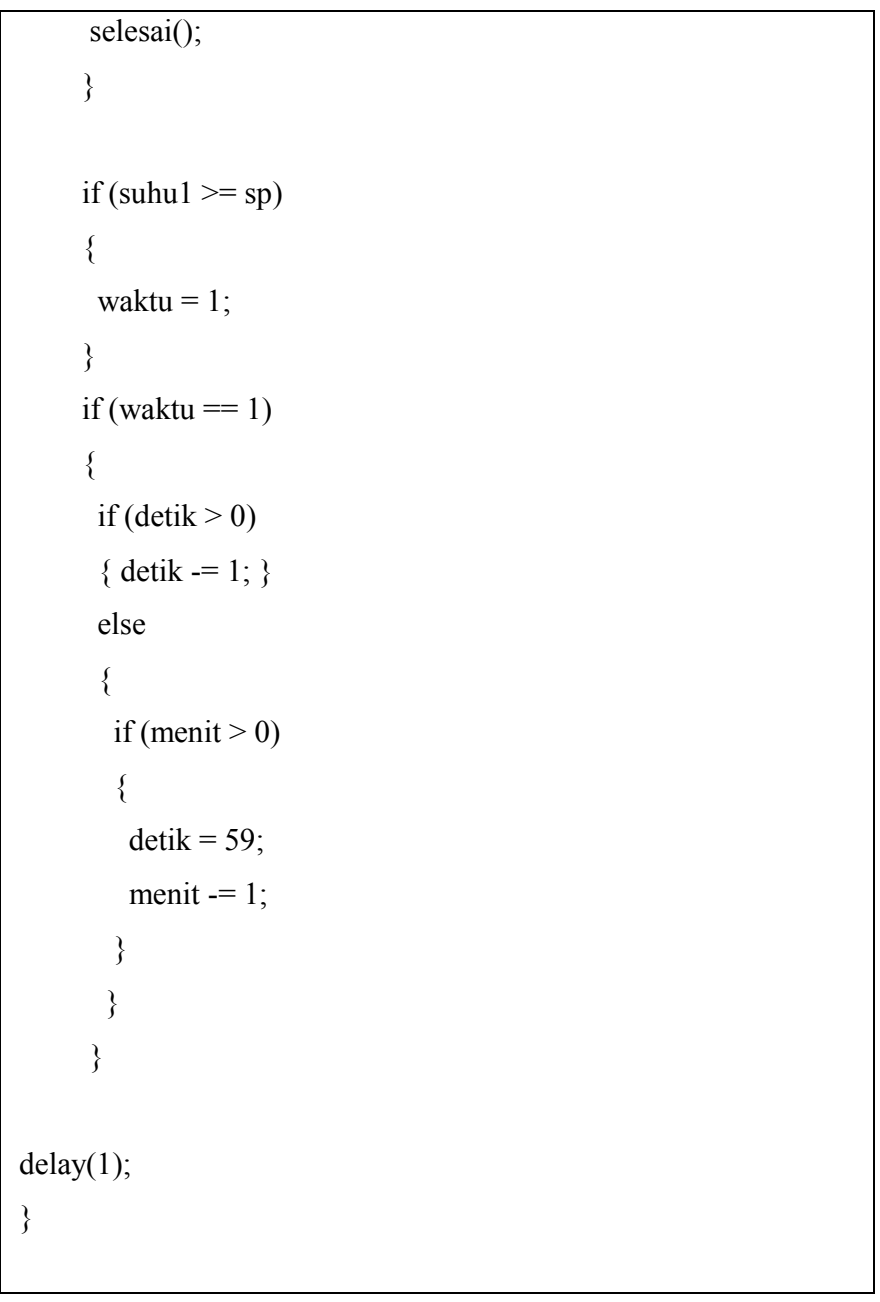

3) Result trial and error to find $k p$, $k i$, and $k d$

In this study, used a trial and error method to find $\mathrm{Kp}, \mathrm{Ki}$, and $\mathrm{Kd}$ value. Here is the result of trial and error with $\mathrm{Kp}$ value is $57, \mathrm{Ki}$ value is 5 and $\mathrm{Kd}$ value is 3.2 .

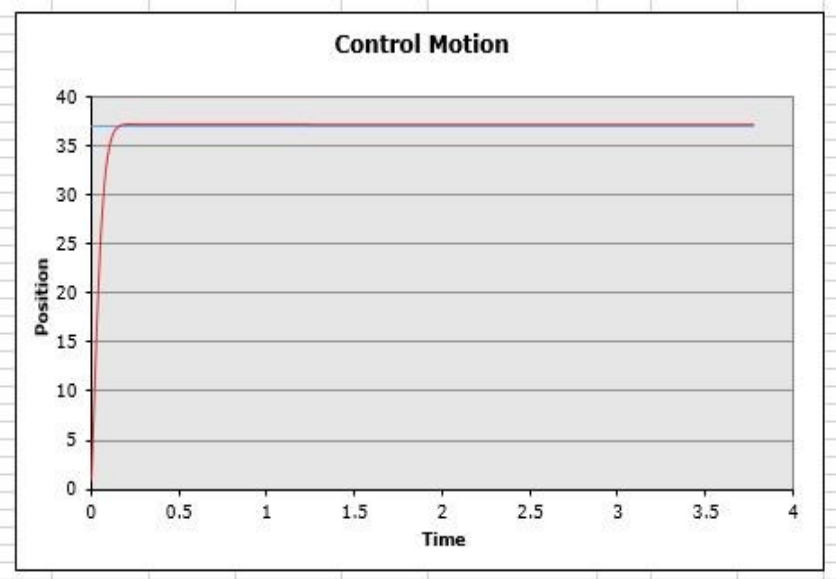

Fig. 4. The trial and error method
From figure 6. it appears the criteria for the desired system have been met without overshoot, rise time and stable control temperature.

\section{4) Result of the temperature measurement.}

The validation of the temperature value shown in the LCD was compared with the digital thermometer. The error was showed in Table I.

TABLE I. THE ERROR OF MEASUREMENT FOR TEMPERATURE BETWEEN THE MODULES AND CALIBRATOR (THERMOMETER).

\begin{tabular}{cccc}
\hline $\begin{array}{c}\text { Set Point } \\
\left({ }^{\circ} \mathrm{C}\right)\end{array}$ & $\begin{array}{c}\text { Modul } \\
\text { Average } \\
\left({ }^{\circ} \mathrm{C}\right)\end{array}$ & $\begin{array}{c}\text { Thermometer } \\
\text { average }\left({ }^{\circ} \mathrm{C}\right)\end{array}$ & Error $(\%)$ \\
\hline 37 & 37,05 & 37,5 & 1,21 \\
\hline 40 & 39,91 & 40,33 & 1,06 \\
\hline 45 & 44,94 & 45,32 & 0,85 \\
\hline 50 & 49,88 & 50,18 & 0,61 \\
\hline 55 & 54,91 & 55,15 & 0,43 \\
\hline 60 & 59,93 & 59,93 & 0,11
\end{tabular}

Comparison of data retrieval is done by comparing modules with comparison devices (digital thermometer) that are done 6 times in each set point and taken on average. from the data above it shown that the highest error is $1.21 \%$ on set point $37{ }^{\circ} \mathrm{C}$ and the lowest error is $0.11 \%$ on set point $60{ }^{\circ} \mathrm{C}$.

5) Result of the Timer Measurement

The validation of the timer value shown in the LCD was compared with the stopwatch. The error was showed in Table II.

TABLE II. THE ERROR OF MEASUREMENT FOR TIMER BETWEEN THE MODULES AND STANDARD UNIT (STOPWATCH).

\begin{tabular}{cccc}
\hline $\begin{array}{c}\text { Timer set } \\
\text { (minute) }\end{array}$ & $\begin{array}{c}\text { Modul average } \\
\text { (minute) }\end{array}$ & $\begin{array}{c}\text { Stopwatch } \\
\text { average } \\
\text { (minute) }\end{array}$ & Error \% \\
\hline 10 & 10.36 & 10 & 3,4 \\
\hline 15 & 15,36 & 15 & 3,4
\end{tabular}

Comparison of data retrieval is done by comparing modules with comparison devices (stopwatch) that are done 6 times in each set point and taken on average. from the data above it shown that the timer has the same error. 


\section{6) Modul result}

The module result was shown in the Fig.5 which includes the front has 5 buttons (up, down, enter, mon, and reset), thermostat, LCD 4X20, heater indicator and water level indicator. the side there is a faucet for disposal of residual water incubation.
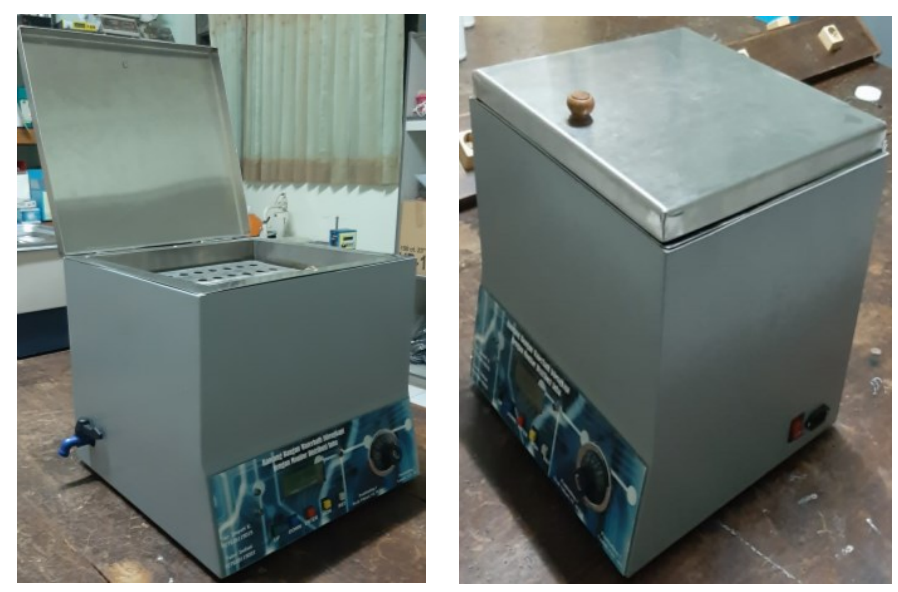

Fig. 5. The Design of a water bath

\section{Discussion}

The water bath design has been examined and test completely in this study. After comparing the results between the module and the measuring instrument, the smallest error in the temperature parameter is $0.11 \%$ and the biggest error is $1.21 \%$. while for the timer error is $3.4 \%$. Based on the results obtained this module can be used properly because still on the maximum limit error value less than $5 \%$. The used of PID control with trial and error methods for temperature control can work well and be able to maintain the temperature setting during the incubation process.

\section{Conclusion}

This study has shown that Sensors DS18B20 are capable of being used to perform temperature readings on water media properly, except that for the use of an Arduino timer program it is not recommended to be used in conjunction with DS18B20 sensors. it can affect the inaccuracies that are read on the display with the actual time. used of PID control can work well and be able to maintain the temperature setting during the incubation process. The design of this tool is expected to be able to overcome the problem of temperature instability in the water bath for the sample incubation process

\section{REFERENCES}

[1] Sipakainga, "ILMU ANALIS_ WATERBATH_," 2014. [Online]. Available: http://sipakainga-17.blogspot.com/2014/06/apaitu-waterbath.html. [Accessed: 25-Oct-2018].

[2] Adam, "WATERBATH (ADAM MUAMAR TEM 2015)," 2015. [Online]. Available: https://www.scribd.com/presentation/359532270/WATERBATHADAM-MUAMAR-TEM-2015-pptx. [Accessed: 25-Oct-2018].

[3] T. A. Salim, "MODIFIKASI WATERBATH MERK MEMMERT BERBASIS MIKROKONTROLLER AT89S51,” S, 2011.

[4] C. Andreas, "WATERBATH DENGAN SISTEM KONTROL SUHU ON-OFF DILENGKAPI TIMER DAN SISTEM PENGISIAN AIR OTOMATIS BERDASARKAN DETEKSI LEVEL AIR BERBASIS MIKROKONTROLLER AT89S51,” 2011.

[5] C. Febriana, "Modifikasi Waterbath Berbasis Digital dengan Pemilihan Waktu," 2014.

[6] A. Maulidia, "WATERBATH DILENGKAPI dengan SAFETY CONTROL dan INDIKATOR LEVEL AIR BERBASIS ARDUINO,” 2016. 